\title{
Teacher Absences in the Commonwealth of Virginia:
}

\section{An Analysis of Patterns and Predictors and Implications for Policy}

\author{
Donna L. Eagle, Henrico County Public Schools \\ William J. Glenn, Virginia Tech University
}

\begin{abstract}
The purpose of this study was to analyze selected variables for public schools and districts in Virginia to determine the relationship of school and policy characteristics to teacher absences. This study included two research questions: What is the relationship between certain school district policy provisions and teacher absenteeism? What is the relationship between certain school characteristics and teacher absenteeism?
\end{abstract}

The analysis for this study involved computing descriptive statistics, correlating continuous variables, and running multiple regressions for each dataset (school and district for each year) to determine the predictors of the dependent variable, chronically absent teachers. Although the school models were significant, neither was a particularly strong predictor of chronically absent teachers, only accounting for $15.2 \%$ of variation (2011-2012 model with $\left.R^{2}=.152\right)$ and $9.6 \%$ of variation $\left(2013-2014\right.$ model with $\left.R^{2}=.096\right)$ that is predicted by the independent variables. Nevertheless, there were independent policy and school variables that were significant predictors in both school years. The most prominent variables included total leave, personal leave maximums, income protection provisions (sick leave banks, short-term disability), free and reduced lunch population percentage of a school, pupil/teacher ratio of the school, and the grade level of the school (elementary, middle, and high).

During the 2013-2014 school year, over one quarter of public school teachers nationally were absent from the classroom more than 10 days (United States Department of Education, 2016), a level of absenteeism that we define as chronically absent. Roughly one sixth of teachers missed more than 18 days in a school year (National Council on Teacher Quality [NCTQ], 2014).
The chronic absentee rate varied greatly by school, but over 6.5 million students attended schools in which over half of the teachers were chronically absent (United States Department of Education, 2016). On any given day, over $5 \%$ of teachers were absent from their jobs (United States Department of Education, 2012; NCTQ, 2014), which greatly exceeds the 2.9\% national rate of absence for full time wage and salaried American workers (Bureau of Labor Statistics, 2013).

The issue of teacher absences should be examined for several key reasons. First, the financial impact of teacher absence is significant. It has been estimated that the payroll for substitutes totals over $\$ 4$ billion annually, which equates to roughly $1 \%$ of federal, state, and local spending on K-12 public education (Miller, 2008; United States Department of Education, 2007). The NCTQ (2014) found that the 40 school districts they studied spent approximately $\$ 400$ million on substitute teachers. Dividing this total by the number of regular (non-substitute) teacher yields a figure of roughly $\$ 1,800$ spent per regular teacher on substitutes. In addition, substitute teachers often must undergo the same background screening as a full time teacher in order to comply state requirements. Second, teacher absences negatively impact student achievement (Clotfelter, Ladd, \& Vigdor, 2007; Herrmann \& Rockoff, 2012; Miller, Murnane, \& Willett, 2007; Tingle, Schoeneberger, Wang, \& Algozzine, 2012). Third, teacher absences are not equitably distributed, but tend to occur more frequently in schools with lower student outcomes (Pitkoff, 1993; Roby, 2013), low-income families (Clotfelter et al., 2007; Pitkoff, 1993), and/or high percentages of students from racial/ethnic minority backgrounds (Miller, 2012).

Research specific to teacher absenteeism is limited 
due to the fact that teacher absenteeism data is not reported to state education departments. While research on the topic has been scarce and mixed (Clotfelter et al., 2007; Ehrenberg, Ehrenberg, Rees, \& Ehrenberg, 1991; Miller et al., 2007, Rosenblatt \& Shirom, 2005, 2006; Van Dick \& Wagner, 2001), findings indicate that policy affects absences (Clotfelter et al., 2007; Jacob, 2013). The purpose of this study was to examine selected variables contained in the Office for Civil Rights 2011-2012 and 2013-2014 Civil Rights Data Collection (CRDC), in the National Center for Educational Statistics, and in district policies to determine if patterns exist among teacher absences in public school districts in the Commonwealth of Virginia and determine the relationship between teacher absences and organizational and policy characteristics. These years were selected because they were the most recent years for which data were available at the time we conducted the study.

\section{Predictors of Teacher Absenteeism}

Researchers purport that group and organizationallevel factors, such as organizational culture, may influence absenteeism rates (Fitzgibbons, 1992; Nicholson \& Johns, 1985; Rentsch \& Steel, 2003; Rhodes \& Steers, 1990). Research reviewed on the factors causing absenteeism is varied but can be categorized into four conceptual themes: organizational characteristics, teacher characteristics, organizational policies, and culture.

\section{Organizational Characteristics}

Organizational characteristics of schools include the conditions and structures under which the school operates. Several organizational characteristics can impact the amount of leave that teachers use each year. Larger schools and districts tend to have more teacher absences (Miller et al., 2007; Rosenblatt \& Shirom, 2006), as do schools with larger staff sizes (Bridges \& Hallinon, 1978; Winkler, 1980). Ost and Schiman (2017) suggest that teachers who teach larger classes tend to be absent less frequently than other teachers, and teacher absences are less frequent in high school (Clotfelter et al., 2007; Speas, 2010, Tingle et al., 2012). The evidence is mixed regarding whether teacher absences occur more frequently in elementary or middle schools (Clotfelter et al., 2007; Miller et al., 2007; Rosenblatt \& Shirom, 2006; Scott \& McClellan, 1990; Speas, 2010; Tingle et al., 2012). Teachers employed at low SES schools tend to be absent more frequently than teachers at schools with students from higher income families (Clotfelter et al., 2007; Pitkoff, 1993). Miller (2012) found the same results at schools with greater percentages of Black and/or Hispanic stu- dents. Ehrenberg et al. (1991), Miller (2008), and Pitkoff (1993) found that higher student absenteeism is associated with higher teacher absenteeism. Finally, Pitkoff (1993) found that higher teacher absence is associated with higher student dropout rates.

\section{Teacher Characteristics}

Several teacher characteristics may impact the amount of leave that teachers use each year. Clotfelter et al. (2007) found that teachers that had a master's degree (Ost \& Schiman, 2017), higher state examination scores, held National Board certification, or graduated from a very competitive college had fewer absences. Teachers who recently acquired tenure tend to have higher absence rates than pre-tenured teachers and longer-term veteran teachers (Clotfelter et al., 2007; Miller et al., 2007; Speas, 2010). Female teachers missed more time than males, both in terms of absence frequency and duration or number of days (Clotfelter et al., 2007; Miller, 2008; Miller, 2012; NCTQ, 2014; Ost \& Schiman, 2017; Scott \& McClellan, 1990; Scott \& Wimbush, 1991; Tingle et al., 2012). Ehrenberg et al. (1991) found that the greater the proportion of teachers in a school older than 55, the lower the usage of sick leave (Ehrenberg et al., 1991). Research findings support the logical premise that the further a teacher lives from their school, the more they are absent (Scott \& McClellan, 1990; Scott \& Wimbush, 1991; Winkler, 1980). Job satisfaction combined with organizational practices and absence culture influence teacher attendance (Rhodes \& Steer, 1990).

\section{Organizational Policies}

Organizational factors relating to worker absences have often been ignored (Stoetzer, et al., 2014). The work of Ehrenberg et al. (1991) remains the most important study of the topic in American schools. Ehrenberg et al. (1991) made several interesting findings about how organizational policies influence the number of absences. They found that the larger the number of leave days permitted by the school district, the higher the number of leave days that were taken. Similarly, they also found that districts with unlimited accumulation of sick leave experience a lower usage of leave, presumably so teachers could save up sick days (Ehrenberg et al., 1991). This finding squares with the finding that the existence of buyback provisions of unused sick leave days also lowers the annual usage of leave days taken by staff personnel (Ehrenberg et al., 1991). In a related point, Pitkoff (1993) noted that when teachers with historically low absence rates approached the maximum accumulation of leave, absence rates increased, which could be reflective of a 
"use it or lose it" mentality. Teachers with job protection tend to be absent more frequently and tend to have a higher rate of chronic absenteeism (Jacob, 2013). Several researchers have found that requiring teachers to provide proof of illness and report the absence directly to the school principal also reduces the number of absences--particularly Monday or Friday absences (Farrell \& Stamm, 1988; Hubbell, 2008; Winkler, 1980).

\section{Culture}

Organizational culture plays an important role in absences. A study from Finland showed that teachers who had lower levels of satisfaction at school were less likely to be absent due to sickness (Ervasti et al., 2012). Similarly, a general study of leadership behaviors and employee absences, also from Finland, found that workers in a relaxed and supportive atmosphere had fewer sick-related absences than those working in a tense environment (Piirainen, Räsänen, \& Kivimäki, 2003). These findings make sense in the context of education because teachers have discretion over their absences, so a teacher who is satisfied with her job location is less likely to call in sick than a teacher who is not happy.

\section{Methods}

The purpose of this study was to examine selected school and policy data to determine if any relationship exists between teacher absences and school and policy characteristics. The data for teacher, school, and district variables were extracted from the Office for Civil
Rights 2011-2012 and 2013-2014 CRDC, with the exception of a percentage of students receiving free or reduced lunch and pupil/teacher ratio, which came from the National Center for Educational Statistics for the respective school years.

In order to determine the policy variables for this study, we conducted a content analysis of the leave policies of the 132 school districts in Virginia. The analysis was very unobtrusive as the authors of the various polices had no awareness of the policies being analyzed, yielding minimal chance that the act of measuring would impact the data (Weber, 1990). This content analysis generated categorical and continuous data for the policy variables.

\section{Population}

The population for this study included all public schools in the state of Virginia that reported in the 2011-2012 and 2013-2014 CRDC and were coded to one of the 132 public school districts in Virginia. Schools included traditional public schools (preschool through 12th grade), alternative schools, career and technical education schools, and charter schools. There were 1,931 schools included in the study in the 2011-2012 dataset and 1,912 schools in the 2013-2014 dataset with all 132 public school districts included in both years. These data are summarized in Table 1.

\section{Data Collection Procedures}

The 2011-2012 and 2013-2014 CRDC datasets for the state of Virginia contained the following variables:

Table 1

Schools Counts by Level for 2011-2012 and 2013-2014

\begin{tabular}{lcccc}
\hline School Level & $\begin{array}{c}2011-2012 \\
\text { Total dataset }\end{array}$ & $\begin{array}{c}\text { 2011-2012 } \\
\text { Excluding } \\
\text { Outliers }\end{array}$ & $\begin{array}{c}2013-2014 \\
\text { Total Dataset }\end{array}$ & $\begin{array}{c}\text { 2013-14 Ex- } \\
\text { cluding Outli- } \\
\text { ers }\end{array}$ \\
\hline Alternative & 48 & 43 & 40 & 37 \\
Combined (Pre-K-12) & 1 & 1 & 1 & 1 \\
Elementary (Pre-K-6) & 1,118 & 1,031 & 1,107 & 1,059 \\
Elementary/Middle (Pre-K & 50 & 46 & 47 & 45 \\
$-8)$ & 339 & 310 & 340 & 326 \\
Middle (5-9) & 12 & 11 & 13 & 13 \\
Middle/High (6-12) & 322 & 304 & 320 & 309 \\
High (7-12) & 24 & 18 & 27 & 27 \\
Pre-K Center & 17 & 16 & 17 & 17 \\
Special Education Center & 1,931 & 1,780 & 1,912 & 1,834 \\
\hline Total & 727 & & 725 & \\
Title I School & & & & \\
\hline
\end{tabular}


Title 1 school, the grade range of the school, type of school, number of teachers in their first year of teaching, number of teachers in their second year of teaching, size of student enrollment, size of teaching workforce, teachers who missed more than 10 days, and students who were chronically absent (2013-14 only for the final variable). Based on the grades in each school, each school was categorized as follows: alternative, combined (contained grades K-12), elementary (contained grades pre-K through 6), elementary/ middle (contained grades Pre-K-8), middle (contained grades 6-9), middle/high (contained grades 7-12), high (contained grades 7-12), preschool, and special education centers. The remaining two school characteristics studied (percentage of students receiving free or reduced lunch and pupil/teacher ratio) were downloaded for the respective years from the National Center for Educational Statistics.

Leave policies for the 132 Virginia public school districts were compiled. District leave policies are available on the Internet for most school districts for public viewing. District leave policies also are subject to the Virginia Freedom of Information Act (FOIA). For any policy variables not specified clearly in policy language, a clarifying standardized email was sent to the human resource contact listed in the Virginia Public School Division Staff directory maintained online by the Virginia Department of Education.

A content analysis examining each district's leave policies was conducted. Data were coded into the following categories: personal leave amount granted annually, personal leave maximum accumulation amount, personal leave expiration, maximum accumulation amount of sick leave, total days of sick leave granted annually, total days of leave granted annually, smallest increment for use of sick leave, income protection plans, monetary value of sick leave day upon retirement, and maximum amount of sick leave payout.

After examining the data in aggregate, some of the data were not considered for inclusion in the regression studies. The maximum sick leave accumulation amount was not included because it was completely missing from a large number of districts that lacked that particular policy provision. Total days of sick leave granted annually were not included, as some districts combine personal leave into the sick leave granted annually. Instead, a field with the sum of the personal and sick leave granted annually was used. Finally, for many districts without a cap on the maximum amount or days to be paid, the maximum amount of sick leave payout is dependent on the number of days a particular teacher has accumulated.
Therefore, these data were not included in the regression studies.

\section{Data Analysis Procedures}

The analysis for this study involved computing descriptive statistics, correlating the continuous variables, and running multiple regressions for each dataset. The dependent variable studied was the percentage of teachers absent for more than 10 days at each school or district. The independent variables were comprised of school variables and policy variables and included number of teachers, inexperienced teachers (two years or less), school level, Title I, student enrollment, free or reduced lunch percentage, student absence percentage, pupil/teacher ratio, personal leave amount, personal leave maximum, personal leave expires, leave amount per year, smallest increment for use of sick leave, sick leave maximum, monetary value of a sick leave day, and income protection.

Descriptive statistics were run in order to properly analyze the data, determine outliers, and identify any issues with the data. Histogram and plot and whisker diagrams were reviewed along with the skewness for each distribution. Some data were excluded based on this analysis.

Using multiple regression, we examined the relationship of the dependent variable, chronically absent teachers (the percentage of teachers absent for more than 10 days at each school), with independent variables to find significant effects. Variables that were found to have interactive effects--student enrollment and number of teachers--were explored by running the regressions with and without both variables and checking the variance inflation factor. Ultimately student enrollment was omitted from the regressions.

\section{Results}

The sample for this study consisted of all public schools and districts in the state of Virginia that reported in both the 2011-2012 and 2013-2014 CRDC. School levels are presented in Table 2. Also presented in Table 2 are the data, excluding outliers and schools with suspect teacher absence data (presented in the section on outliers).

\section{Excluded Data}

We excluded some data in order to eliminate outliers and probable data errors. We removed districts (and the schools in them) that reported $0 \%$ chronically absent teachers; schools that reported $93 \%$ or more chronically absent teachers; the handful of schools that reported $57 \%$ or more inexperienced teachers; and districts with values per sick day of $\$ 285$, as these 
Table 2

District Dataset Means and Standard Deviations for 2011-2012 and 2013-2014

\begin{tabular}{|c|c|c|c|c|}
\hline School Continuous Variables & $\begin{array}{c}2011-12 \\
M\end{array}$ & 2011-12 SD & $\begin{array}{c}\text { 2013-14 } \\
M\end{array}$ & 2013-14 SD \\
\hline Chronically absent teachers & .3395 & .1455 & .288 & .1494 \\
\hline Inexperienced teachers & .0932 & .0429 & .1002 & .0670 \\
\hline Free or reduced lunch percentage & .4754 & .1657 & .4901 & .1671 \\
\hline \multicolumn{5}{|l|}{ Policy Continuous Variables } \\
\hline Personal leave amount & 2.57 & .7203 & 2.59 & .7267 \\
\hline Personal leave maximum & 3.92 & 1.737 & 3.95 & 1.76 \\
\hline Leave amount per year & 12.56 & .9695 & 12.59 & .987 \\
\hline Monetary value of a sick leave day & 40 & 24.44 & 40.40 & 24.995 \\
\hline
\end{tabular}

were several times the mean value. We ran the regression analysis both with and without the outliers, in order to determine the extent to which the outliers influenced the results.

\section{Descriptive Statistics}

After excluding the above data, descriptive statistics were rerun for each dataset.

Tables 2 and 3 show the extent of the chronic absence issue in Virginia public schools. Approximately one third of the teacher work force missed 10 or more days of work in both years. At an average of approximately 48 teachers (rounded up from 47 to keep the number whole) per school, 16 teachers were chronically absent on average.

Table 4 shows the school district policy variables that may influence the chronic absence rate. Of primary interest is the fact that the vast majority of dis- tricts did not have sick leave maximums or expiration of personal leave.

\section{Correlation Results}

Pearson correlations were calculated among the continuous predictive variables for both years at the school and district levels. At the school level, the dependent variable chronically absent teachers had a significant correlation $(p<0.05)$ with two independent variables in both years: pupil teacher ratio $(r=0.151$ and $r=0.115)$ and leave amount per year $(r=0.144$ and $r=$ $0.205)$, meaning schools with higher pupil teacher ratios or greater leave amounts per year tended to have a higher percentage of chronically absent teachers.

\section{Multiple Linear Regression Results}

To determine the statistical significance and relative importance of each predictive variable, we created a model for each dataset (four sets in total) and exam-

Table 3

Schools Dataset Means and Standard Deviations for 2011-2012 and 2013-2014

\begin{tabular}{lcccc}
\hline School Continuous Variable & $2011-12$ & $2011-12 S D$ & $2013-14$ & $2013-14 S D$ \\
\hline Chronically absent teachers & $M$ & .193 & .329 & .186 \\
Number of Teachers & .352 & 29.99 & 47.42 & 29.36 \\
Inexperienced teachers & 46.91 & .071 & .104 & .084 \\
Student enrollment & .093 & 441.88 & 668.12 & 442.37 \\
Free or reduced lunch percentage & .675 .39 & .233 & .447 & .235 \\
Pupil/Teacher ratio & .434 & 2.74 & 15.80 & 3.37 \\
Student Absence & 15.63 & - & .124 & .108 \\
Policy Continuous Variables & - & & & \\
Personal leave amount & & .637 & 2.62 & .645 \\
Personal leave maximum & 2.60 & 1.88 & 4.12 & 1.88 \\
Leave amount per year & 4.09 & .944 & 12.58 & .968 \\
Monetary value of a sick leave day & 12.57 & 26.04 & 39.18 & 26.46 \\
\hline
\end{tabular}


Table 4

Summary of Policy Variable Counts for 2011-2012 and 2013-2014 District Dataset

\begin{tabular}{lccc}
\hline Policy Variable & Yes & No & Total \\
\hline Smallest increment for use of sick leave is & 98 & 34 & 132 \\
half day & 39 & 93 & 132 \\
Sick leave maximum exists & 106 & 25 & 131 \\
Income protection plan exists & 7 & 125 & 132 \\
Personal leave expires & \\
\hline
\end{tabular}

ined the unstandardized coefficient beta weights and the standardized beta weights of each predictive variable. In addition, $R^{2}$ was used to examine the relationships between the various predictive variables and the dependent variable. We also ran regression models for each dataset including the outliers.

The results were similar for the models with and without the outliers. We have reported the results for the models that excluded the outliers because the dataset without the outliers appears to us to be more accurate, given some clear data errors in the outliers. The overall regressions were significant at the school level both years: for 2012, $F(22,1,655)=14.123, p$ $<.0001, R^{2}=.152$ and for 2014, $F(22,1,699)=8.247, p$ $<.0001, R^{2}=.096$. The regressions were not significant for any of the district models: for 2012, $F(10,114)=$ $1.726, p=.0832$, and $R^{2}=.1315$ and for 2014, $F(11,113)$ $=1.4638, p=.1550$ and $R^{2}=.1247$. The difference in the results at the school vs. the district level most likely can be explained by the difference in the sample sizes of the two levels (over $n=1,600$ vs. $n=125$, respectively).

Table 5 summarizes the regression results at the school level for both years. Combining the results enables us to visualize which independent variables were significant on a consistent basis for both school year datasets.

Policy variables. Several policy variables significantly predicted teacher absences in both school year models. Schools with income protection plans were estimated to have a lower percentage of teachers missing more than 10 days. This result was unexpected because the existence of income protection plans, which provide insurance against the loss of pay once accumulated leave is exhausted, should result in increased teacher absences. As would be expected and logical, every extra day of total leave granted per year resulted in a higher percentage of teachers chronically absent. Also as expected, districts with larger personal leave maximums had a larger percentage of teachers absent more than 10 days. Finally, although the variables of the existence of sick leave maximums and the requirement of using sick leave in whole or half day increments were significant in both school year models, the signs of the coefficients were opposite for these respective variables in the two school year models, which limits the estimates' usefulness, as there was no consistent pattern in the two school years.

School variables. Two school variables also were significant in both school year models. Schools with a higher free and reduced lunch percentage had increased teacher absences. This is not surprising because research has consistently shown that the lower the socio-economic status of students enrolled in a school, the higher the rate of teacher absence (Clotfelter et al., 2007; National Council on Teacher Quality, 2014; Pitkoff, 1993). Schools with higher pupil teacher ratios also had more teachers absent in excess of 10 days. Both free and reduced lunch percentage and pupil teacher ratio were significant in both models, though the magnitude of the coefficients for both free and reduced lunch and pupil teacher ratio was small.

\section{Discussion}

The research literature to date indicates that teacher absences may be related to various school and policy variables. The evidence from this research study also supports a relationship for some school and policy variables. Conclusions from the results are examined further below, and recommendations for further research are suggested.

\section{Policy Variables}

The findings in this study support prior studies that showed that teachers tend to take more leave when the school district offers a larger number of leave days. In both study years, every extra day of total leave granted per year (sum of sick leave and personal leave granted annually) was estimated to increase teacher absences more than 10 days by 3\% (2011-2012 model) and 3.5\% (2013-2014 model). Also as would be expected, in both school years, the districts with larger 
Table 5

Regression Results for Both School Datasets

\begin{tabular}{lcccccc}
\hline Independent Variable & $2011-12$ & $2011-12$ & $2011-12$ & $2013-14$ & $2013-14$ & $2013-14$ \\
& Estimate & $p$-value & $B$ & Estimate & $p$-value & $B$ \\
\hline Alternative School & 0.0725 & 0.3707 & 0.0207 & -0.0558 & 0.4501 & -0.0180 \\
Combined School & 0.1807 & 0.3118 & 0.0231 & -0.0381 & 0.8294 & -0.0050 \\
Elementary/Middle School & 0.0374 & 0.1841 & 0.0314 & 0.0021 & 0.9416 & 0.0018 \\
Free or Reduced Lunch & 0.1223 & $<0.0001$ & 0.1490 & 0.0641 & 0.0175 & 0.0818 \\
High School & 0.0341 & 0.0567 & 0.0670 & -0.0455 & 0.0105 & -0.0931 \\
Income Protection Plan & -0.0532 & 0.0003 & -0.0876 & -0.0462 & 0.0016 & -0.0786 \\
Leave Amount Per Year & 0.0299 & $<0.0001$ & 0.1496 & 0.0350 & $<0.0001$ & 0.1866 \\
Middle School & 0.0510 & 0.0007 & 0.1027 & 0.0175 & 0.2234 & 0.0369 \\
Middle/High School & 0.0147 & 0.8065 & 0.0059 & -0.0732 & 0.1703 & -0.0332 \\
Monetary Value of Sick Leave & -0.0009 & $<0.0001$ & -0.1164 & -0.0002 & 0.1743 & -0.0342 \\
Day & & & & & & \\
Number of Teachers & -0.0002 & 0.3408 & -0.0308 & 0.0004 & 0.0484 & 0.0631 \\
Personal Leave Amount & -0.0169 & 0.0477 & -0.0568 & 0.0045 & 0.5813 & 0.0160 \\
Personal Leave Expires & -0.0028 & 0.9113 & -0.0027 & 0.0738 & 0.0033 & 0.0727 \\
Personal Leave Maximum & 0.0061 & 0.0297 & 0.0603 & 0.0082 & 0.0029 & 0.0850 \\
Preschool Center & -0.0238 & 0.6621 & -0.0101 & 0.0422 & 0.3088 & 0.0247 \\
Pupil/Teacher Ratio & 0.0142 & $<0.0001$ & 0.2048 & 0.0059 & $<0.0001$ & 0.1088 \\
Sick Leave Maximum & -0.0712 & $<0.0001$ & -0.1381 & 0.0355 & 0.0040 & 0.0733 \\
Sick Leave Used in Half Days & 0.0453 & 0.0001 & 0.1178 & -0.0401 & 0.0006 & -0.1081 \\
Special Education Center & -0.1245 & 0.3208 & -0.0226 & 0.1342 & 0.0674 & 0.0432 \\
Student Absences & & & & -0.0959 & 0.0339 & -0.0565 \\
Inexperienced teachers & -0.3703 & $<0.0001$ & -0.1293 & -0.0398 & 0.4624 & -0.0181 \\
Title I School & 0.0186 & 0.1853 & 0.0479 & -0.0423 & 0.0025 & -0.1128 \\
\hline
\end{tabular}

personal leave maximums were estimated to have a larger percentage of teachers absent more than 10 days.

Ehrenberg et al. (1991) showed that the existence of buyback provisions of unused sick leave days reduced the number of leave days taken annually. Buyback provisions upon retirement exist in 130 of the 132 school districts in the Commonwealth of Virginia and in this study. The two districts that did not have buyback provisions were Albermarle and Martinsville. In the 2011-2012 dataset, data from Albermarle was excluded, leaving only one district with five schools without buyback provisions. Therefore, the relationship of buyback provisions and the percent of teachers that was absent more than 10 days was not studied. However, the related variable monetary value of sick leave day upon retirement was examined and found to be a significant predictor in the 2011-2012 schools model. As the value of the sick leave days increased, the number of teachers absent more than 10 days decreased slightly.
Winkler (1980) found that the existence of income protection plans, which provide insurance against loss of wages once accumulated leave is exhausted, resulted in higher short-term absenteeism. In this study, 106 of 132 districts offered income protection plans of either a sick leave bank or a short-term disability plan. Compared to schools with no income protection plans, schools with income protection plans are estimated to have a lower percentage of teachers missing more than 10 days in both school models. While this is not congruent with Winkler's research, it could be because this study did not isolate short-term absenteeism and only examined the relationship to the percentage of teachers that missed more than 10 days.

The data in the study do not permit us to test Jacobs' (2013) argument that teacher job protections correspond to a higher rate of teacher absences. The continuing contract laws in Virginia apply to all school districts, so the issue of job protection is linked completely with that of teacher experience. The results of this study show that inexperienced teachers - those 
without job protection--were chronically absent at a significantly lower rate than more experienced teachers. This finding lends support to Jacobs' argument, but it is not conclusive. The result could relate more to factors other than job protection, such as age (younger teachers may be healthier), the inability of inexperienced teacher to have stockpiled as many sick days as veteran teachers, or a variety of other factors.

\section{School Variables}

The socioeconomic status of students has been found to have an impact on teacher absence (Pitkoff, 1993). In various studies (Clotfelter et al, 2007; NCTQ, 2014), teachers at schools serving higher percentages of free and reduced lunch students were absent more. Findings in this study for both school years support the existing research that the higher a school's free and reduced lunch percentage, the higher the percent of teachers that are estimated to miss more than 10 days. However, the magnitude of the coefficients is small: 0.122\% (2011-2012 model) and .064\% (2013-2014 model).

The relationship of chronically absent teachers to the pupil-teacher ratio was not found in the research reviewed. The closest parallel was Ost and Schiman's (2017) finding that elementary school teachers with larger class sizes tend to be absent less frequently than teachers with smaller class sizes. Class size and pupilteacher ratio are not identical, so comparisons between this study and that one might differ for that reason. However, the results of this study showed that as the pupil-teacher ratio increased in both school years analyzed, as did the predicted percentage of teachers that missed more than 10 days. It is logical to assume that as the student-teacher ratio increases, so might teacher absences due to the increased workload and corresponding fatigue of the teacher. Further study of pupil-teacher ratios in relationship to teacher absences is warranted, both due to the inconsistency in the literature and the possible effect of teacher absences on class size reduction policies.

Class size reduction is one of the most popular education reforms among parents, but it can be difficult to implement due to its high cost (Mathis, 2017). The majority of research shows that class size reduction benefits students, particularly among disadvantaged students (Mathis, 2017). The evidence also suggests that class size reduction conveys long-term economic benefits to individual students and to society as a whole (Mathis 2017). However, a school district facing tight budgetary demands may not find small class sizes to be beneficial in its short-term calculus. However, if further study shows that reducing class size also reduces the amount money spent on substitute teachers needed per classroom teacher, such a short term economic consideration might make class size reduction a more viable model for school systems.

\section{Summary and Recommendations}

Overall, this investigation did reveal evidence that both school and policy variables are related to the number of teachers that are absent more than 10 days per year. Considering the magnitude of the problem, with $35.2 \%$ and $32.9 \%$ of teachers absent more than 10 days during the 2011-2012 and 2013- 2104 school years, respectively, in the Commonwealth of Virginia public schools, this issue merits further study.

This research informs policy for districts in Virginia. While the total leave granted per year (sum of personal and sick leave granted annually) was a significant predictor of the percentage of teachers that miss more than 10 days, school districts in Virginia have little flexibility in the minimum amount of sick leave. As outlined in the Virginia Administrative Code, 8VAC20-460-10, school districts may offer no less than 10 days of sick leave each year. However, there are no statutory requirements about personal leave. Based on this research, limiting the number of personal leave days that can be taken in one school year may reduce teacher absences. In addition, a policy provision that provides for excess personal leave to carry over into sick leave could also reduce teacher absences.

There were several variables that were significant predictors of an increased percentage of chronically absent teachers that, in our professional experience, are variables associated with increased workload for teachers. Those variables include percentage of free and reduced student population and student/teacher ratio. Staffing ratios designed carefully around these variables could lead to reduced teacher absence. Although adding personnel increases costs, the benefit may reduce teacher absences, resulting in cost savings in substitute payroll expense.

Nearly one in every three teachers in Virginia is absent more than 10 days per year. In the present state of teacher accountability and challenging budgets, it is critical that districts gain a better understanding of teacher absences and take measures to improve teacher attendance. The result could yield increased student academic success and savings for school districts. To quote a line from the National Council on Teacher Quality Study (2014) that is worth repeating, "We may be overlooking one of the most basic, solvable and cost effective reasons why schools may fail to 
make educational progress" (p. 14).

\section{References}

Bridges, E., \& Hallinan, M. (1978). Subunit size, work system interdependence, and employee absenteeism. Educational Administration Quarterly, 14(2), 2442.

Bureau of Labor Statistics. (2013). Labor force statistics from the current population survey, (2013) table 4. Retrieved from http://www.bls.gov/cps/ cpsaat46.pdf

Clotfelter, C. T., Ladd, H. F., and Vigdor, J. L. (2007). Are teacher absences worth worrying about in the U.S.? (NBER Working Paper 13648) Retrieved from http://www.nber.org/papers/w13648

Ehrenberg, R. G., Ehrenberg, R. A., Rees, D. I., \& Ehrenberg, E. L. (1991). School district leave policies, teacher absenteeism, and student achievement. The Journal of Human Resources, 26, 72-105.

Ervasti, J., Kivimäki, M., Puusniekka, R., Luopa, P., Pentti, J., Suominen, S., Ahola, K., Vahtera, J., \& Virtanen, M. (2012). Students' school satisfaction as predictor of teachers' sickness absence: a prospective cohort study. European Journal of Public Health, 22(2), 215-219.

Farrell, D., \& Stamm, C. (1988). Meta-analysis of the correlates of employee absence. Human Relations, 41(3), 211-227.

Fitzgibbons, D. E. (1992). A critical reexamination of employee absence: The impact of relation contracting, the negotiated order, and the employment relationship. Research in Personnel and Human Resources Management, 10, 73-120

Herrmann, M. A., \& Rockoff, J. E. (2012). Worker absence and productivity: Evidence from teaching. Journal of Labor Economics, 30(4), 749-782. https:/ / doi.org/10.1086/666537

Hubbell, C. (2008). Reducing teacher absenteeism. WASB Report, Summer 2008.

Jacob, B. (2013). The effect of employment protection on worker effort: Evidence from public schooling. Journal of Labor Economics, 31(4), 727-761.

Mathis, W. J. (2017). The effectiveness of class size reduction. Education Digest, 82(5), 60.

Miller, R. (2008). Tales of teacher absence: New research yields patterns that speak to policy makers. Washington, DC: Center for American Progress. Retrieved from http://cdn.americanprogress.org/wpcontent/uploads/issues/2008/10/pdf/ teacher_absence.pdf
Miller, R. (2012). Teacher absence as a leading indicator of student achievement. Washington, DC: Center for American Progress. Retrieved from https:// www.americanprogress.org/issues/education/ report/2012/11/05/40371/teacher-absence-as-aleading-indicator-of-student-achievement/

Miller R. T., Murnane, R. J., \&Willett, J. B. (2007). Do teacher absences impact student achievement? Longitudinal evidence from one urban school district. (NBER Working Paper No. W13356) Retrieved from http://www.nber.org/papers/ w13356

National Center for Education Statistics (n.d.). Elementary/secondary information system, 2011-12 (public schools). Retrieved November 19, 2016, from https://nces.ed.gov/ccd/elsi/ tableGenerator.aspx

National Center for Education Statistics (n.d.). Elementary/secondary information system, 2013-14 (public schools). Retrieved November 19, 2016, from https://nces.ed.gov/ccd/elsi/ tableGenerator.aspx

National Council on Teacher Quality (June, 2014). Roll call: The importance of teacher attendance. Retrieved from http://www.nctq.org/dmsStage/ RollCall_TeacherAttendance

Nicholson, N., \& Johns, G. (1985). The absence culture and the psychological contract: Who's in control of absence? Academy of Management Review, 10(3), 397-407.

Ost, B., \& Schiman, J. C. (2017). Workload and teacher absence. Economics of Education Review, 57, 20-30.

Piirainen H., Räsänen K., \& Kivimäki M. (2003). Organizational climate, perceived work-related symptoms and sickness absence: A populationbased survey. Journal of Occupational Environmental Medicine, 45(2),175-184.

Pitkoff, E. (1993). Teacher absenteeism: What administrators can do. NASSP Bulletin, 77(551), 39-45.

Rentsch, J. R., \& Steel, R.P. (2003). What does unitlevel absence mean? Issues for future unitlevel absence research. Human Resource Management Review, 13, 182-202.

Rhodes, S., \& Steers, R. (1990). Managing employee absenteeism. Reading, MA: Addison Wesley.

Roby, D. (2013). Teacher attendance effects on student achievement: Research study of Ohio schools. Education, 134(2), 201-206.

Rosenblatt, Z., \& Shirom, A. (2005). Predicting teacher absenteeism by personal background factors. Journal of Educational Administration, 43(2), 209 - 225. 
Rosenblatt, Z., \& Shirom, A. (2006). School ethnicity and governance influences on work absence of teachers and school administrators. Educational Administration Quarterly, 42(3), 361-384.

Scott, D., \& McClellan, E. (1990). Gender differences in absenteeism. Public Personnel Management, 19(2), 229-253.

Scott, D., \& Wimbush, J. (1991). Teacher absenteeism in secondary education. Educational Administration Quarterly, 27(4), 506-529.

Speas, C. (2010) Teacher absences: Types, frequency, and impact on student achievement. Wake County Public School System, 2007-2008. Evaluation and Research Report No. 09.37.

Stoetzer, U., Bergman, P., Åborg, C., Johansson, G., Ahlberg, G., Parmsund, M., \& Svartengren, M. (2014). Organizational factors related to low levels of sickness absence in a representative set of Swedish companies. Work, 47(2), 193-205. doi:10.3233/ WOR-2012-1472

Tingle, L.R., Schoeneberger, J., Wang, C, Algozzine, B., \& Kerr, E. (2012). An analysis of teacher absence and student achievement. Education, 133(2), 367382.

United States Department of Education. (2012). Schools and staffing survey 2011-2012. [Data file]. Retrieved from http://nces.ed.gov/surveys/sass/ tables_list.asp\#2012

United States Department of Education (2016). 20132014 Civil rights data collection: A first look. Retrieved from https://ed.gov/about/offices/list/ ocr/docs/2013-14-first-look.pdf

United States Department of Education (n.d). 2011 2012 Civil rights data collection part 1 and part 2 data definitions. Retrieved from http://ocrdata.ed.gov/ datadefinitions

United States Department of Education (n.d). 2013-2014 Civil rights data collection part 1 and part 2 data definitions. Retrieved from http:/ / ocrdata.ed.gov/ datadefinitions

United States Department of Education (n.d). Civil rights data collection, 2011-2012 school year. [Data file].

United States Department of Education (n.d). Civil rights data collection, 2013-2014 school year. [Data file].

Van Dick, R., \& Wagner, U. (2001). Stress and strain in teaching: A structural equation approach. British Journal of Educational Psychology, 71, 243-259.

Virginia Administrative Code, 8VAC20-460-10. Allowances. 1980.

Weber, R. P. (1990). Basic content analysis (2nd Ed.). Newbury Park, CA: Sage.
Winkler, D. R. (1980). The effects of sick-leave policy on teacher absenteeism. Industrial and Labor Relations Review, 33(2), 232-240. 